\title{
EDITORIAL
}

\section{A Towering Babel of Risk Information in the COVID-19 Pandemic: Trust and Credibility in Risk Perception and Positive Public Health Behaviors}

Arch G. Mainous III, PhD

(Fam Med. 2020;52(5):317-9.)

doi: 10.22454/FamMed.2020.530121

n December 2019, the acute respiratory illness now known as novel coronavirusinfected pneumonia (NCIP) occurred in Wuhan, Hubei Province, China. Coronavirus disease (COVID-19) is an infectious disease that over the previous several months has become a worldwide pandemic. As such, the public has been bombarded with information about COVID-19 from many different sources providing information on symptoms, behaviors to prevent transmission and contracting the virus, and importantly, one's risk of contracting the disease and risk of severe outcomes and death. Sources like the Johns Hopkins Coronavirus Map constantly update identified cases and deaths throughout the world (https://coronavirus.jhu.edu/map.html). ${ }^{1}$ It is frightening to see one column listing the number of identified cases worldwide at more than 550,000 and the number of deaths at more than 25,000 at one point in the day, a higher number later in the same day, and more than 650,000 cases the next day. Further, even international leaders like Prime Minister of the United Kingdom Boris Johnson, and his Secretary of State for Health have tested positive for COVID-19. ${ }^{2}$

Patients are looking for guidance on how to protect themselves and interpretation of their symptoms. How likely am I to get sick? Is this cough just a cough or does it mean that I am likely to die?

\section{Different Sources Have \\ Different Numbers}

Risk perception is part of everyone's decisionmaking process and that perception of risk affects the person's subsequent behavior. ${ }^{3}$ The perception of risk affects compliance with public health messages for positive behaviors. ${ }^{4}$ If one doesn't perceive themselves at risk they will likely not comply with a message like "don't congregate in groups and keep social distance" during the COVID-19 pandemic.

A variety of authorities including the World Health Organization (WHO), the US Centers for Disease Control and Prevention (CDC), the President of the United States, and the Director of the National Institute of Allergy and Infectious Diseases (NIAID), along with many academics and television pundits have provided predictions on the risk of COVID-19 to patients. They have been staggeringly different in their statements of mortality risk and predictions for the number of potential deaths from COVID-19. Countries and municipalities have responded to this plethora of risk models with different strategies to control the pandemic focusing on social distancing. Many young adult patients have refused to comply with the social distancing recommendations to the chagrin of political leaders and public health experts.

From the Department of Health Services Research, Management and Policy, University of Florida, Gainesville, FL. 
An illustration of the inconsistent communication on health risks for COVID-19 among authority figures can be found in the early communication of the mortality risk of COVID-19. Imperial College London's estimate of 2.2 million Americans dying within a year from the COVID-19 pandemic can be contrasted with Dr Anthony Fauci's mortality risk assessment of $1 \%$ mortality rate and a death toll of between 200,000 and 520,000 Americans. This in turn can be contrasted with President Trump's much lower estimate of the severity of the problem..$^{5-7}$ On February 26, President Trump said, "Because of all we've done, the risk to the American people remains very low. ... When you have 15 people, and the 15 within a couple of days is going to be down to close to zero." On February 28, President Trump said, "It's going to disappear. One day, it's like a miracle, it will disappear." So our patients are hearing mortality estimates ranging from “... close to zero" to $2,200,000$ deaths. This is a remarkable disparity and all come from seemingly credible sources.

Polls have shown the confusion among the population about the severity of the disease and the risk to their health. In a poll conducted on March 18-24 by Reuters, $91 \%$ of respondents said that they were somewhat or very familiar with COVID-19. ${ }^{8}$ Patients clearly are not ignorant about the topic, but they are hearing many different things. In an NBC News/ Wall Street Journal poll conducted March 11$13,89 \%$ reported that they had heard "a lot" about the coronavirus and found that $68 \%$ of Democrats were worried that someone in their family could catch the virus, compared with just $40 \%$ of Republicans. ${ }^{9}$

\section{Importance of Trust, Credibility, and Risk Perception}

A number of factors influence perceptions of risk including the source of the message and the credibility and trust of the entity providing the message. To maintain trust, the information presented must be seen as credible and in the best interest of the patient. If only the very ill are tested for COVID-19, then the mortality rate is likely to be much higher than if testing includes individuals who are asymptomatic or have mild disease (estimated to be more than $80 \%$ of those infected are included in the denominator). Many health systems have thus far discouraged testing individuals with mild symptoms because of the limited number of test kits available and the limited amount of personal protective equipment.
Some have commented that many of the risk models have been based on faulty data because the population testing needed to establish a denominator was not done. ${ }^{10}$ If the recommendation on risk is perceived to be based on faulty data it is unlikely to be complied with, thereby exacerbating compliance with the public health intervention and putting patients at risk.

Is the amount of risk presented in a way to indicate a tradeoff between health and economics? Trust cannot be maintained if the entities presenting the health message are perceived as making a recommendation that benefits them economically at the expense of the individual. ${ }^{11}$ The US Preventive Services Task Force does not consider cost in their recommendations as a way to increase trust that the recommendation is based solely on health benefits. Consequently, the COVID-19 pandemic and the associated municipal, state, and country lockdowns have a challenge with trust and perception of risk by patients because of the huge impacts on the economy and patient jobs. Public health officials may present worst-case scenarios without considering economics while politicians are considering jobs in a tradeoff against deaths. The patient needs to understand both the inherent biases in the numbers and the information source to have trust and comply with recommendations like shelter in place or social distancing.

\section{The Role of the Family Physician and the Health System}

What is the role of family physicians in protecting the health of patients during the COVID-19 pandemic and beyond? The patient-physician relationship and the trust engendered between the patient and physician is critical in a time like this. The trust patients put in their physicians to act in their best interest contributes to the effectiveness of medical care, and physicians act as patients' advocates. ${ }^{12}$ Even in the more modern health care system where the high-continuity, one-toone relationship is difficult to maintain and more providers are involved in patient care (eg, within the patient-centered medical home), trust can still be maintained with the overall practice. The message from Christy Ledford, $\mathrm{PhD}$, and LaKesha Anderson, $\mathrm{PhD}$ in this issue of Family Medicine provides insight and direction on the communication that needs to come from family physicians in times of health crisis. ${ }^{13}$ Patients are looking for guidance in times like these. Family physicians can and must play an integral role not only 
in providing treatment, but also in sorting through the numerous voices that patients hear to provide reliable advice and reassurance.

CORRESPONDENCE: Address correspondence to: Dr Arch G. Mainous III, Department of Health Services Research, Management and Policy, University of Florida, Gainesville, FL 32610. 352-273-6073. Fax: 352-273-6075. arch.mainous@ufl.edu.

\section{References}

1. Johns Hopkins University. Johns Hopkins COVID-19 Map: Coronavirus COVID-19 Global Cases by the Center for Systems Science and Engineering. https://coronavirus.jhu. edu/map.html Accessed March 28, 2020.

2. Dewan A, Dean S. Coronavirus strikes UK Prime Minister Boris Johnson, his health secretary and his chief medical adviser. Cable News Network. https://www.cnn.com/2020/03/27/ uk/uk-boris-johnson-coronavirus-gbr-intl/index.html. Published March 28, 2020. Accessed March 28, 2020.

3. Williams DJ, Noyes JM. How does our perception of risk influence decision-making? Implications for the design of risk information. Theor Issues Ergon Sci. 2007;8(1):1-35.

4. Zungu NP, Simbayi LC, Mabaso M, et al. HIV risk perception and behavior among medically and traditionally circumcised males in South Africa. BMC Public Health. 2016;16(1):357.

5. Walker PGT, Whittaker C, Watson O, et al. The Global Impact of COVID-19 and Strategies for Mitigation and Suppression. London, Imperial College London; 2020. https:// www.imperial.ac.uk/media/imperial-college/medicine/sph/ide/ gida-fellowships/Imperial-College-COVID19-Global-Impact26-03-2020v2.pdf. Published March 26, 2020. Accessed March $28,2020$.
6. Bailey R. COVID-19 Mortality rate "ten times worse" than seasonal flu, says Dr Anthony Fauci. Reason. https://reason com/2020/03/11/covid-19-mortality-rate-ten-times-worsethan-seasonal-flu-says-dr-anthony-fauci/. Published March 11, 2020. Accessed March 28, 2020.

7. Blake A. A timeline of Trump playing down the coronavirus threat. The Washington Post. https://www.washingtonpost. com/politics/2020/03/12/trump-coronavirus-timeline/. Published March 17, 2020. Accessed March 28, 2020.

8. Reuters/Ipsos Poll: Coronavirus Tracker, March 18-24, 2020 [press release]. Washington, DC: Ipsos. https://fingfx.thomsonreuters.com/gfx/mkt/13/3885/3841/Topline\%20Reuters\%20 Coronavirus\%2003\%2024\%202020.pdf. Accessed March 28, 2020.

9. NBC News-Wall Street Journal Survey, March 2020. Wasington, DC: Hart Research Asssociates. https:/www.documentcloud.org/documents/6810602-200149-NBCWSJ-March-PollFinal-3-14-20-Release.html. Accessed March 28, 2020.

10. Ioannidis JPA. A fiasco in the making? As the coronavirus pandemic takes hold, we are making decisions without reliable data. Stat. https://www.statnews.com/2020/03/17/a-fiasco-in-the-making-as-the-coronavirus-pandemic-takes-holdwe-are-making-decisions-without-reliable-data/. Published March 17, 2020. Accessed March 28, 2020.

11. Mainous AG III. Physicians should declare financial incentives for recruiting minority ethnic patients into clinical trials. BMJ. 2014;348(may07 4):g2985.

12. Mainous AG III, Smith DW, Geesey ME, Tilley BC. Factors influencing physician referrals of patients to clinical trials. J Natl Med Assoc. 2008;100(11):1298-1303.

13. Ledford CJW, Anderson LN. Communication strategies for family physicians practicing throughout emerging public health crises. Fam Med. 2020;52(5):320-323. 